www.jmscr.igmpublication.org

Impact Factor 5.84

Index Copernicus Value: 83.27

ISSN (e)-2347-176x ISSN (p) 2455-0450

crossref DOI: https://dx.doi.org/10.18535/jmscr/v5i1.90

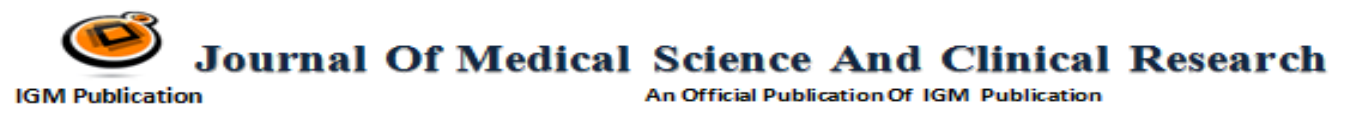

\title{
Public-Private Mix Model in Enhancing Tuberculosis Case Detection in Dakshin Dinajpur
}

\author{
Authors \\ Sukumar Dey ${ }^{1}$, Asok Kumar Biswas ${ }^{2}$, Kalidas Poddar ${ }^{3}$, Debajit Sarkar ${ }^{4}$, Kalyan Sen $^{5 *}$ \\ ${ }^{1}$ Chief Medical Office of Health, Chief Medical Officer of Health,Dakshin Dinajpur,West Bengal,India \\ ${ }^{2}$ Chief Medical Office of Health, Deputy Chief Medical Officer of Health-III, Dakshin Dinajpur,West \\ Bengal, India \\ ${ }^{3}$ Chief Medical Office of Health, District Tuberculosis officer, Dakshin Dinajpur,West Bengal, India \\ ${ }^{4}$ Zonal Program Coordinator, GLRA-INDIA, North Zone, West Bengal,India. \\ ${ }^{5 *}$ Chief Medical Office of Health, District Public Private Mix Coordinator, Dakshin Dinajpur, \\ West Bengal, India \\ Corresponding Author*
}

Kalyan Sen

Chief Medical Office, District Public Private Mix Coordinator, Dakshin Dinajpur,West Bengal,India.

Pnone Number: 7098629610/9434257769, Email: kalyan_bpharm@rediffmail.com

\begin{abstract}
Object- To increase the TB cases detection using proposed trail tool for notification in collaboration with Public-Private Mix model (Charitable Hospital, Private Laboratory, Private Practitioner and Medical retail Shop) in the district of Dakshin Dinajpur, West Bengal, India.

Method- The organizations were selected on the basis of following criteria defined in private- public partnership. The design study showed a change in the TB notification d rate (NR).

Results- Tuberculosis case notification rate after implementation of public-private mix model have increased for the last three month. Chalon and Hili TU showed a good responds regarding private notification. The new trail methodology was applied and twenty four (Table:2) specific retail shops were identified out of nearly 400 Medical retail shops of Dakshin Dinajpur. Simultaneously nearly 168 private notification was gathered from the medical retail shop in the month of December 2016. The new proposed trail tool may help to solve different type of questions like patient history, category of the patient, treatment protocol, patient compliance, follow up, drug resistance, death rate and diagnosis pathway of unregistered patients and we will be also understanding whether the patients is following the standard of TB care in India, So there was a huge need of extending the research to control and eradicate TB from the district like Dakshin Dinajpur as well as India.

Conclusion- Public private mix (PPM) model was effective in increasing the CDR of TB cases in district Dakshin Dinajpur, West Bengal. And the proposed new trail tool may be effective to get the unidentified TB cases who were not registered in the RNTCP, Nikshay portal. The new trail methodology may created a bridge between unregisters case finding and the format provided by the government of India for notification. The tool showed a unique technique to reach the unregister cases of tuberculosis. The last step of the proposed trail tool became the most important mechanism to find out the real purpose of notification from the private stakeholders. It is also is recommended that the public private partnership model in Tuberculosis case detection needs to be taken on a larger scale so as to reduce the huge TB burden in India
\end{abstract}

Keywords-PublicPrivateMix, NR, Tuberculosis, Notification, Standerddeviation. 


\section{Introduction}

The paper reflects the vital role of notification by the public private mix concept to identify the unidentified tuberculosis case detection in Dakshin Dinajpur, West Bengal. The data from the intensified PPM sites have shown an overall increase in the number of TB cases notified under RNTCP. Still now there are a large number of patients are not under the direct purview of the Revised National TB Control Programme (RNTCP). "To address emerging threats to health, new forms of action are needed. There is a clear need to break through traditional boundaries within government sectors, between governmental and nongovernmental organizations, and between the public and private sectors. Cooperation is essential; this requires the creation of new partnerships for health, on an equal footing, between the different sectors at all levels of governance in societies". 'More burden of tuberculosis occur in India than in any other country in the world. An estimated 2.2 million new cases of tuberculosis and 2,80,000 tuberculosis related deaths occurred in 2014, representing one fifth of the global burden of incident cases of tuberculosis and mortality. ${ }^{2}$ The Indian Revised National Tuberculosis Control Programme began large scale nationwide implementation of the World Health Organization's global tuberculosis control strategy (DOTS) in 1998 and has since expanded rapidly. Country-wide coverage is anticipated by April 2006. However, almost large amount of patients with tuberculosis in India may initially need help from the private healthcare sectors, where diagnosis, treatment, and reporting practices often do not meet national or international standards for tuberculosis. ${ }^{3-5}$

Public-private mix has been defined by WHO as strategies that link all healthcare entities within the private and public sectors (including health providers in other governmental ministries) to national tuberculosis programmes for expansion of DOTS activities. ${ }^{6}$ Published reports of publicprivate mix projects indicate that the approach is feasible and effective, but previous evaluations are largely limited to local and individual experiences. ${ }^{7-}$
${ }^{9}$ India has the largest collection of such experiences of public-private mix, few of which to date have been reported. ${ }^{11-14} \mathrm{We}$ describe the effect of a series of pilot public-private mix projects in India on case notification of tuberculosis and treatment outcomes and discuss the potential role of public-private mix in improving tuberculosis control in India. The term notification means that tuberculosis is diagnosed in a patient and reported in the system. From 2013 onwards, the numbers of cases are reported to WHO in the following categories: New pulmonary bacteriologically confirmed TB cases; New pulmonary clinically diagnosed TB cases; New extra pulmonary TB cases, bacteriologically confirmed or clinically diagnosed; Relapse pulmonary bacteriologically confirmed TB cases; Relapse pulmonary clinically diagnosed TB cases; Relapse extrapulmonary TB cases, bacteriologically confirmed or clinically diagnosed; Previously treated cases, excluding relapse cases, bacteriologically confirmed or clinically diagnosed. ${ }^{15}$ Some patients under treatment for active TB disease in the country move to another country before completing treatment. To assist in treatment completion and continuity of care, CTD has developed a process for international notification. Notification of TB control personnel in the patient's country of destination, TB control personnel in that country advise patient to complete treatment, Patient is advised and educated on the importance of completing treatment. ${ }^{16}$

\section{Method}

\section{Study design and study population}

The operational and cross-sectional self monitored structured process was conducted during the months of August to October 2016 to notify the TB patients to identify the unregistered tuberculosis case detection. The organizations involved exclusively and actively in this process is Office of the $\mathrm{CMOH}$, RNTCP Wings, Goverment of West Bengal, Dakshin Dinajpur, German leprosy \& TB relief association Chennai, Dakshin Dinajpur, Wings, West Bengal, private laboratories, one charitable Hospital and 24 Medical Retail Shop of the same district. Simultaneously an innovative trail tool is 
discovered to find out the specific number of patients who were under private practitioner in the districts of Dakshin Dinajpur, West Bengal.

\section{Study Sample}

The organizations were selected on the basis of following criteria: (1) should come within the definition of private- public partnership. (2) Be exclusively and actively involved in health social work and business. The organizations selected for the study were: 1-Holy cross Hospital, Gangarampur. 2-Sonoscan Healthcare Pvt.Ltd, Balurght.3-DishariDiagnostic, Balurght, 4-Ghosh Sonoscan Centre, Gangarampur, 5-Raghunathpur Diagnostic Centre, Balurght and 24 Medical Retail Shop. All the personnel from the above organisations (those who were present at the time of the survey and those who were actively involved in health social work and business) were selected for the survey.

\section{Contribution of public-private mix model to case notification.}

The public-private mix model that primarily involved private hospital, diagnostic centre and medical retail shops were evaluated for a median of 3 months. During this time, 44 new cases of tuberculosis on the basis of sputum smears positive for acid fast bacilli were reported from private laboratory (Table1, Figure1) and 168 patients were found from the Medical Retail Shop of the district (Table 3,Figure 3). In each of the organisation involving private hospital, diagnostic laboratory and Medical Retail Shop with data available from before and after implementation of a public-private mix model, the average quarterly number of positive case notifications increased.
Table 1: Tuberculosis case notification rate after implementation of public-private mix model.

\begin{tabular}{|l|l|l|l|l|l|}
\hline TU Name & August & September & October & Average & SD \\
\hline Hili TU & 3 & 4 & 3 & 3.3333 & 0.6 \\
\hline Khaspur TU & 0 & 0 & 0 & 0 & 0 \\
\hline HarirampurTU & 0 & 0 & 0 & 0 & 0 \\
\hline Bansihari TU & 0 & 0 & 0 & 0 & 0 \\
\hline KumargangTU & 0 & 0 & 0 & 0 & 0 \\
\hline Kusmandi TU & 0 & 0 & 0 & 0 & 0 \\
\hline Tapan TU & 0 & 0 & 0 & 0 & 0 \\
\hline Chalon TU & 5 & 13 & 16 & 11.333 & 5.7 \\
\hline
\end{tabular}

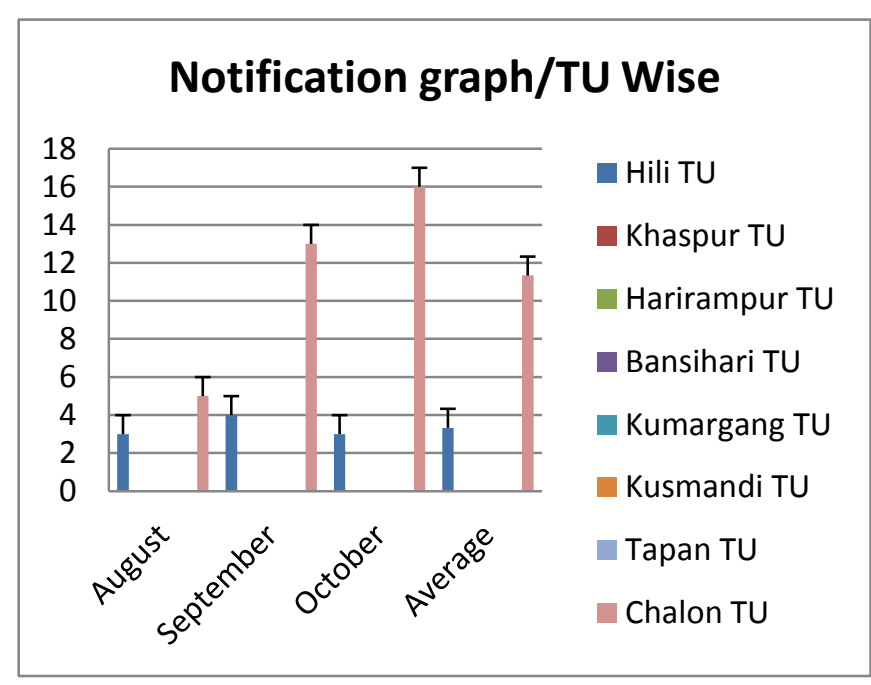

Figure 1 Proposed Trail Tool for notification:

The new trail methodology may create a bridge between unregisters case finding and the format provided by the government of India for notification. The tool showed a unique technique to reach the unregister cases of tuberculosis. Technique is explained in the form of (Figure 2).

Utilization of the format provider for notification: Monthly Stock report of the Anti TB Medicine Sold in the district should be collected from the Direct Stockist. The report will help us to get the specific information regarding the retail medical shops that use to sale Anti TB Drugs. From the retail medical shops Unidentified Patients Details can be recovered for notification. The staffs of RNTCP wings (STS-Senior treatment supervisor) will take the details \& will generate to the PPM Coordinator. And then patient visit is required for informing him/her regarding the DOTS provided by Government of India to return the patient in the RNTCP-DOTS system. 


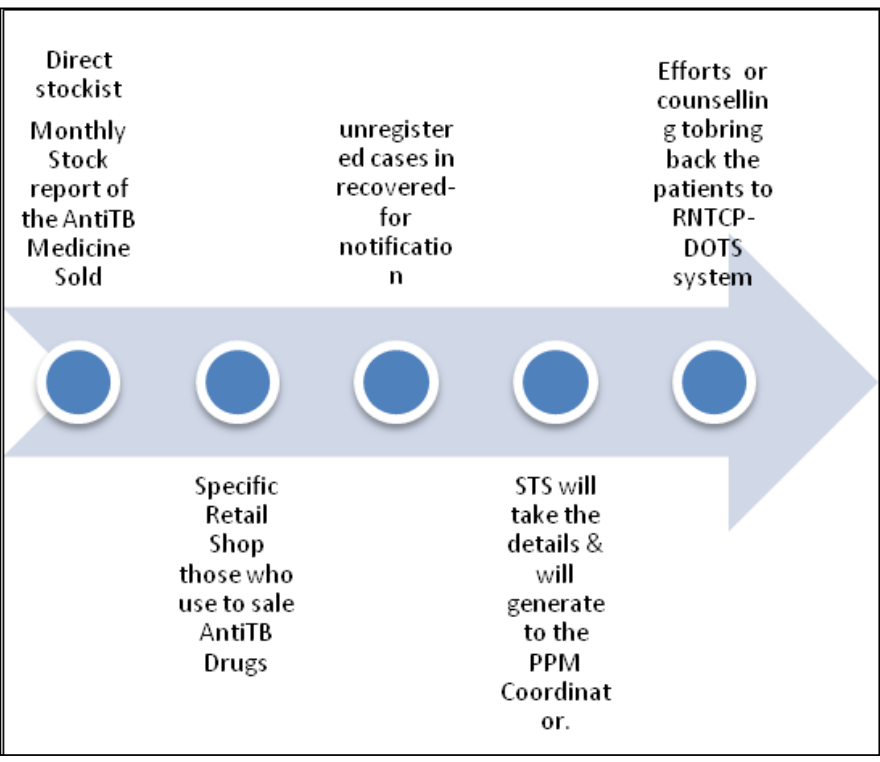

Figure 2: Proposed Trail Tool for notificationModel

Table 2: Name of the Medical Retail shop

\begin{tabular}{|c|c|}
\hline PLACE & NAME OFD THE PHARMACY \\
\hline KHASPUR & AROTI MEDICAL STORES \\
\hline GANGARAMPUR & $\begin{array}{l}\text { GHOSH MEDICAI HALL } \\
\text { MITRO MEDICAL AGENCY } \\
\text { SAGARIKA ENTERPRISE } \\
\text { INDIA DRUG HOUSE } \\
\text { THE DRUG CENRE }\end{array}$ \\
\hline KARDAHA & HARIDASHI PHARMACY \\
\hline KUMARGANJ & DAKHYA PHARMACY \\
\hline NAYABAZAR & USHA MEDICAI STORES \\
\hline KUSUMUNDI & CHAUDHURY MEDICAL \\
\hline HILI & $\begin{array}{l}\text { QUANTAM DRUGS } \\
\text { MONDOL DRUG HOUSE }\end{array}$ \\
\hline TRIMOHINI & SARKAR PHARMACY \\
\hline PATIRAM & $\begin{array}{l}\text { JANAKALAYAN PHARMACY } \\
\text { RAKA MEDICINE }\end{array}$ \\
\hline BUNIADPUR & $\begin{array}{l}\text { JANATA MEDICAL STORE } \\
\text { MUKTI AND SONS }\end{array}$ \\
\hline BALURGHAT & $\begin{array}{l}\text { LOKNATH MEDICAL STORES } \\
\text { NANDA PHARMACY } \\
\text { NEW ROY PHARMACY } \\
\text { GHOSH MEDICINE, } \\
\text { SONALI MEDICAL AGENCY } \\
\text { ROY MEDICAL STORES } \\
\text { MR PHARMACEUTICALS }\end{array}$ \\
\hline
\end{tabular}

Table 2: Indicate the name of the medical retail shop those who sale AntiTB drugs in the district of Dakshin Dinajpur,West Bengal.

Table 3: Notification from Medical Retail shop of Dakshin Dinajpur.

\begin{tabular}{|l|c|c|c|c|}
\hline TU Name & August & September & October & Average \\
\hline Hili TU & 1 & 1 & 2 & 1.3333333 \\
\hline Khaspur TU & 0 & 0 & 2 & 0.6666667 \\
\hline HarirampurTU & 8 & 8 & 8 & 8 \\
\hline Bansihari TU & 10 & 2 & 15 & 9 \\
\hline KumargangTU & 0 & 1 & 2 & 1 \\
\hline Kusmandi TU & 0 & 0 & 3 & 1 \\
\hline Tapan TU & 1 & 1 & 3 & 1.6666667 \\
\hline Chalon TU & 20 & 30 & 50 & 33.333333 \\
\hline
\end{tabular}

Figure 3:

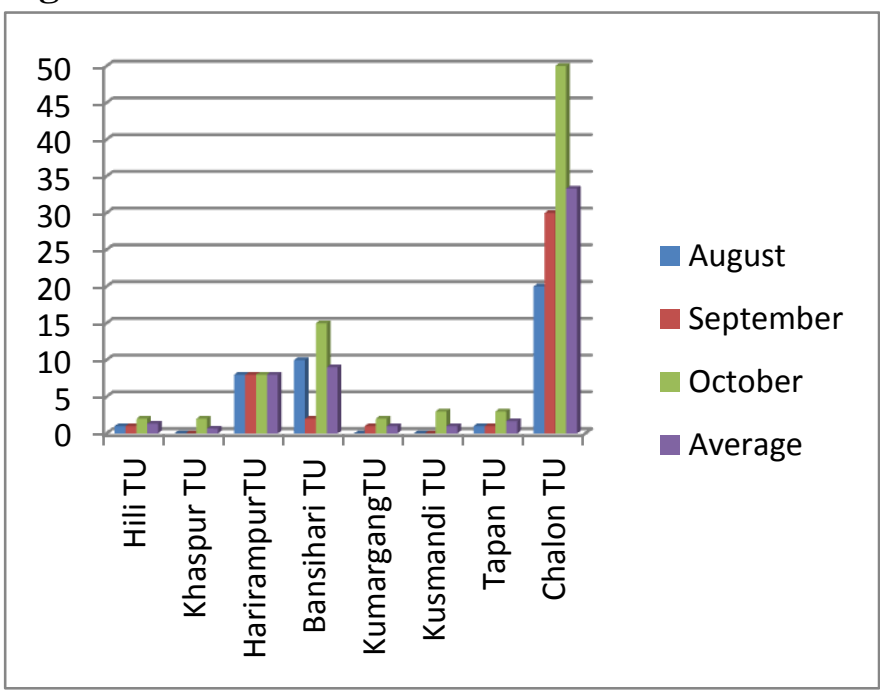

\section{Results}

The (Figure: 1\& Table: 1) clearly define that Tuberculosis case notification rate after implementation of public-private mix model have increased for the specific three months. Chalon and Hili TU showed a good responds regarding private notification. The new trail methodology was applied and twenty four(Table 2) specific retail shops were identified out of nearly 400 Medical retail shops those who sale Anti TBdrugs in Dakshin Dinajpur. Simultaniously nearly 168 private notification was gathered from the medical retail shop in the month of December 2016.

\section{Discussion}

The public private mix model was a newer concept in Dakshin Dinajpur so we faced an initial difficulty in involving all the stakeholders but the response received was encouraging. There was an increase in case detection rate of tuberculosis by involving private organizations. It was found that the private notification in Chalon TU was increasing in rapid manner .This means the concept of DOTS in that specific area was not clear / reaches to the population of the area. Intensification of the ACSM program should be increased on that area. So we can propose a private DOTS centre on that area. In the case of notification the government has provided a format to collect the unregister names of the tuberculosis patients but the methodology of working was not clear. So a unique technique to 
reach the unregister cases of tuberculosis was formed. And a trail was done maintaining the proposed protocol. It was found that the stakeholder (Medical Retail Shop owns) actively generated nearly 168 names .Following the pathway the effectiveness of the work may increase. The work of the field staff may have reduced. This technique can help to solve different type of questions like patient history, category of the patient, treatment protocol, patient compliance, follow up, drug resistance, death rate and diagnosis pathway of unregistered patients and we will be also understanding whether the patients is following the standard of TB care in India, So there was a huge need of extending the research to control and eradicate TB from the district like Dakshin Dinajpur as well as India.

\section{Conclusion}

Public private mix (PPM) model was effective in increasing the CDR of TB cases in district Dakshin Dinajpur, West Bengal. And the proposed new trail tool may be effective to get the unidentified TB cases who were not registered in the RNTCP, Nikshay portal. The new trail methodology may created a bridge between unregisters case finding and the format provided by the government of India for notification. The tool showed a unique technique to reach the unregister cases of tuberculosis. The last step of the proposed trail tool became the most important mechanism to find out the real purpose of notification from the private stakeholder. It is also is recommended that the public private partnership model in Tuberculosis case detection needs to be taken on a larger scale so as to reduce the heavy TB burden in India

\section{Limitations}

\section{This study has several limitations}

Firstly, we were not able to involve the entire private organisation and private practitioners working in the area because some of the organisation was reluctant to join the partnership due to the fact that they may lose their patients. So 100 percent cases were not been registered under RNTCP.
Secondly, few of the cases may not come to the system for more faith on the private practitioner and private organisation by the patients.

Thirdly, the final step of the new proposed trail may requires more systemic technique to revert the patient in the standard for TB care in India (STCI).

\section{Acknowledgements}

The communicating author is thankful to All the members of RNTCP wings, BCDA and GLRA (GLRA India has initiated innovative projects such as TB case contact (house hold \& social) screening in Kochi, Kerala, MDR TB home based care projects in Delhi \& Jaipur and E-compliance treatment adherence project in Jaipur slums. GLRA is a sub-recipient of Global Fund Round 9 TB ACSM projects in West Bengal - Axshya India until September 2015 and also part of the New Funding Model (NFM) projects in 9 districts of W.B.) to perform this study.

\section{Reference}

1. WHO. Jakarta: The Fourth International Conference on Health Promotion: New Players for a New Era-Leading Health Promotion into the 21st Century; 1997. [Last retrieved on 2010 Nov 02]. Jakarta declaration on leading health promotion into the 21st Century. from 21 to 25 July 1997. Available

from: http://www.who.int/hpr/NPH/docs/jakartade claration en.pdf .

2. World Health Organization. Global tuberculosis control 2005: surveillance, planning, financing. Geneva: WHO, 2005. ReportNo :WHO/HTM/TB/2005.349. www. who.int/entity/tb/publications/global_report/ 2005/pdf/Full.pdf (accessed 1 Oct 2005).

3. Prasad R, Nautiyal RG, Mukherji PK, Jain A, Singh K, Ahuja RC. Treatment of new pulmonary tuberculosis patients: what do allopathic doctors do in India? Int $\mathbf{J}$ Tuberc Lung Dis 2002;6: 895-902.[PubMed]

4. Uplekar M, Juvekar S, Morankar S, Rangan $S$, Nunn $P$. Tuberculosis patients and 
practitioners in private clinics in India. Int $\mathbf{J}$ Tuberc Lung Dis 1998;2: 324-9. [PubMed]

5. World Health Organization. The behaviour and interaction of $\mathrm{TB}$ patients and private for-profit health care providers in India: a review. Geneva: WHO, 1997. Report No WHO/TB/97.223. http://whqlibdoc.who.int/ hq/1997/WHO_TB_97.223.pdf (accessed 11 Jan 2005).

6. World Health Organization. Public-private mix for DOTS: report of the second meeting of the PPM subgroup for DOTS expansion. Geneva: WHO; 2004. Report No WHO/HTM/TB/2004.338. http://whqlibdoc. who.int/hq/2004/WHO_HTM_TB_2004.338 .pdf (accessed 11 Jan 2005).

7. Klein SJ, Naizby BE. Creation of a tuberculosis directly observed therapy provider network in New York City: a new model of public health. J Public Health Manag Pract 1995;1: 1-6. [PubMed]

8. Quy HT, Lan NT, Lonnroth K, Buu TN, Dieu TT, Hai LT. Public-private mix for improved TB control in Ho Chi Minh city, Vietnam: an assessment of its impact on case detection. Int J Tuberc Lung Dis 2003;7: 464-71. [PubMed]

9. Newell JN, Pande SB, Baral SC, Bam DS, Malla P. Control of tuberculosis in an urban setting in Nepal: public-private partnership. Bull World Health Organ 2004;82: 92-8. [PMC free article] [PubMed]

10. Mantala MJ. Public-private mix DOTS in the Philippines. Tuberculosis (Edinb) 2003;83: 173-6. [PubMed]

11. Murthy KJ, Frieden TR, Yazdani A, Hreshikesh P. Public-private partnership in tuberculosis control: experience in Hyderabad, India. Int J Tuberc Lung Dis 2001; 5: 354-9. [PubMed]

12. Rangan SG, Juvekar SK, Rasalpurkar SB, Morankar SN, Joshi AN, Porter JD. Tuberculosis control in rural India: lessons from public-private collaboration. Int $\mathrm{J}$ Tuberc Lung Dis 2004; 8: 552-9. [PubMed]

13. Arora VK, Lonnroth K, Sarin R. Improved case detection of tuberculosis through a public-private partnership. Indian J Chest Dis Allied Sci 2004;46: 1-17. [PubMed]

14. Ambe G, Lonnroth K, Dholakia Y, Copreaux J, Zignol M, Borremans N, et al. Every provider counts: effect of a comprehensive public-private mix approach for TB control in a large metropolitan area in India. Int J Tuberc Lung Dis 2005; 9: 562-

8. [PubMed]

15. http://www.who.int/healthinfo/indicators/20 15/chi_2015_45_tb_notification.pdf.

16. https://www.cdc.gov/tb/programs/internation al/. 